\title{
Cognitive and social functioning correlates of employment among people with severe mental illness
}

\begin{abstract}
:
We assess how social and cognitive functioning is associated to gaining employment for 213 people diagnosed with severe mental illness taking part in employment programs in Andalusia (Spain). We used the Repeatable Battery for the Assessment of Neuropsychological Status and the Social Functioning Scale and conducted two binary logistical regression analyses. Response variables were: having a job or not, in ordinary companies (OCs) and social enterprises (SEs), and working in and OC or not. There were two variables with significant adjusted odds ratios for having a job: "attention" and "Educational level". There were five variables with significant odds ratiosfor having a job in an OC: "Sex", "Educational level", “Attention", "Communication", and "Independence-competence". The study looks at the possible benefits of combining employment with support and social enterprises in employment programs for these people and underlines how both social and cognitive functioning are central to developing employment models.
\end{abstract}

Keywords: Serious Mental Illness; Cognitive function; Social function; Employment, competitive employment; Social firms. 


\section{Introduction}

The World Health Organisation's (2013) Comprehensive Mental Health Action Plan 2013-2020, called for 'prioritized attention and engagement' in achieving the 'human right' of employment for people with mental health disorders. Few would question that employment is an essential component in the recovery processes of people with serious mental illness (SMI) (Boardman, Grove, Perkins \& Shepherd, 2003; López, 2010; Perkins, Raines, Tschopp \& Warner, 2009; Provencher, Gegg, Mead \& Mueser, 2002). Work in today's societies provides people with the financial resources for autonomy and social participation and encourages the construction and real exercise of a social identity of citizenship. But there is also sufficient information illustrating that employment is hard to obtain and even harder to hold on to for people with this type of problem, with jobless rates among them often ranging between $80 \%$ and 90\% (Boardman et al., 2003; López, 2010), way above the rates for the general population.

Although there is no clear agreement on this point, different factors affect access to and being able to hold on to a job for people with this type of disability (Butler, Howard, Choi \& Thornicroft, 2010; Mueser, Salyer \& Mueser, 2001). Beyond the not always clear effect of sociodemographic variables, there is data supporting the role of clinical variables related to symptomatology, social functioning and in particular cognitive functioning (memory, attention and executive functions), as factors which determine the success or failure of employment programs (Bell \& Bryson, 2001; Kaneda, Jayathilak \& Meltzer, 2009; McGurk \& Mueser, 2003; McGurk \& Mueser, 2004). However, the relative role of each of these variables and their relations of causality are not easy to establish and continue to generate controversy (Burns et al., 2009; Addington \& Addington, 1999; Green, 2006; Green, Kern, Braff \& Mintz 2000; Mueser, Salyers \& Mueser, 2001).

The consensus is greater on the role of cognitive functioning, including the promising results of programs aimed at improving it (Lysaker, Davis, Bryson \& Bell, 2009; McGurk, Mueser, De Rosa \& Wolfe, 2009; McGurk \& Wykes, 2008). Although important initiatives are underway to agree procedures for research and more specialized care (August, Kiwanuka, McMahon \& Gold, 2012), it is still difficult to find valid and reliable procedures which can be applied to clinical and occupational environments (Gold, Queern, Iannone \& Buchanan, 1999; Hobart, Goldberg, Bartko \& Gold, 1999).

There are differences between the American and European contexts for employment programs for people with SMI, although there is growing consensus over the effectiveness of employment models with support in the ordinary market (Bond, Drake \& Becker, 2008).

In Europe employment programs have been developed based on Social Enterprises which combine the basics of real, market-competitive companies with their social role of employing people with difficulties (Warner \& Mandiberg, 2006; Fioritti et al, 2014; Gilbert et al, 2013). Specifically,within the framework of psychiatric reform in Andalusia, an autonomous region in southern Spain, an employment program is currently underway for people with SMI, based on the articulation of both models (employment in the ordinary market and social firms) and on the coordination between public mental health services and Employment Orientation and Support Services run by a public foundation, Andalusian Foundation for Social Integration of people with Severe Mental Illness (FAISEM), which works for the social integration of these people (López, 2010; Warner \& Mandiberg, 2006). 
We think that social enterprises in Andalusia do not employ people in the same way as traditional, non-competitive jobs (i.e., vocational rehabilitation or sheltered jobs in social or health services). The characteristics of these jobs means that they have more in common with the definition of competitive employment provided by Waghorn, Saha \& McGrath (2014). Social firms in Andalusia are in fact competitive companies operating in the free market. They are self-sustaining, operate in general productive sectors and are managed by business people. People with and without disabilities work fulltime in these firms; they can all reach positions of responsibility, and their salary depends on their productivity in line with general legal regulations. The difference is that these companies have to hire a minimum number of people with disabilities. This gives them certain tax exemptions and makes them eligible for public funding, as occurs in other economic sectors in Spain and Europe; but this funding can never exceed $15 \%$ of the company's turnover. This is why we believe thatthe traditional distinction between competitive and non-competitive employment may givethe wrong idea about users' employment experiences.

In relation to the specific characteristics of the people receiving this support, the definition of Andalusia's mental health services is compatible with international criteria of SMI (Ruggieri, Leese, Thornicroft, Bisoffi \& Tansella, 2000), including mainly diagnoses of schizophrenia and to a lesser degree bipolar disorder, severe depression and borderline personality disorder, but always with the added criteria of prolonged duration and important disability. These are aspects which limit the specific role of the diagnosis emphasizing the difficulties of cognitive and social functioning.

Within this framework, this study explores the characteristics of a group of people with this type of disorder participating in FAISEM employment programs from 2008-2010. It compares the sociodemographic variables and social and cognitive functioning variables among those who did not obtain employment and those who did, respectively, in social enterprises and ordinary market companies; it also uses regression models to obtain a more precise picture of these relations. As such, this study responds to the call from WHO (2013) to attain 'crucial information and indicators' relating to social/economic outcome data including employment among persons with mental disorders.

\section{Method}

\section{Participants}

The final sample consisted of 213 Caucasians (146 men and 67 women) taking part in employment programs for people with SMI in Andalusia (Spain) in the year 2010. The percentage of users who accepted to participate in the research was $88.75 \%$. The number of users choosing not to participate was 27. They were split into three groups according to their employment situation in 2010 (62 employees in social enterprises, 20 in ordinary companies and 131 unemployed). The three groups had similar ages and a similar percentage of diagnoses of schizophrenia, with some differences in sex and educational level (higher percentage of women and higher educational levels in the people employed in ordinary companies). All the users taking part were informed and gave their written consent. The selection and execution of the study was supervised to ensure compliance with ethical standards by FAISEM.Their mean age was 39.71 years (S.D. 7.88), a low level of educational attainment (64.9\% with no formal studies or incomplete compulsoryeducation) and a diagnosis included in the SMI group, mainly 
schizophrenia and related disorders (73\%). We split educational level into three categories in our analysis. "Incomplete compulsory education" included people who either dropped out of compulsory education prematurely (that in Spain involves schooling up to 16 years) or did not complete it successfully. The second level was "completed compulsory studies". The third level was "Baccalaureate-University", and included people who finished the baccalaureate and either stopped studying or went on to university.

\section{Instruments}

We assessed the cognitive function using first of all the Mini Mental Status Examination (MM), a classic neuropsychological screening tool (Folstein, Folstein\& McHugh, 1975), with a suitably validated Spanish version (Lobo et al., 1999).

After that we used the Repeatable Battery for the Assessment of Neuropsychological Status (RBANS) (Randolph, 1998) which is more complex but can also be applied in the context of services and with reasonable psychometric properties (Gold et al., 1999; Hobart et al., 1999; Loughland, Lewin, Carr, Sheedy \& Harris, 2007). It includes five index scores (immediate memory, construction visuospatial, language, attention and delayed memory) and a total scale score. The subtests that belong to each index score are the following: immediate memory (list learning and story memory); visuospatial construction(figure copy and line orientation); language (picture naming and semantic fluency); attention (digit span and digit symbol); delayed memory (list learning free recall, list learning recognition, story memory free recall and figure free recall).This battery has been used over the last decade in several groups of patients with schizophrenia, with a mean time of application of 30 minutes and a total score validity of 0.8 (Loughland et al., 2007). It has also shown a correlation of up to 0.4 with other neuropsychological screening instruments such as the MM. There are normative data for patients with schizophrenia (Wilk et al., 2004) based on a sample of 575 subjects (301 men and 184 women) in health services in the USA.

We assessed social functioning using a reduced and suitably validated Spanish version of the Social Functioning Scale (SFS) (Alonso et al., 2008; Birchwood, Smith, Cochrane, Wetton \& Copestake, 1990). It has 15 items and 5 subscales (isolation, communication, independence-competence, independence-execution and occupational activity), with the last not being used because it is a variable explored directly in the study. The Kansas Satisfaction Scale and the Quality of Life Self-Report Questionnaire were also used to assess subjective satisfaction and wellbeing of users.

\section{Procedure}

Our study was cross-sectional and the first analysis of data was carried out at the end of 2010. The sample was divided into three groups according to the employment situations of usersas noted above. A clinical psychologist who was an expert at using RBANS with people with SMI assessed participants individually in the Support Services offices. Before thefinal assessment, the interviewer explained to participants what they had to do and made them practice each task once to ensure they fully understood.Initially, basic socio-demographic data were obtained through an interview. After that, the Mini Mental Status Examination, RBANS, and SFS were applied. 


\section{Statistical analysis}

We conducted the analysis in three stages using the SPSS 21 statistical package. In the first, we obtained the direct score and the one converted from the RBANS, analyzing its internal validity using Cronbach's alpha. We also analyzed results according to the educational level by way of variance analysis. Secondly, we used an ANOVA univariant analysis to cross-check information from the RBANS, the SFS and the sociodemographic variables with the occupational situation (unemployed, employed in social company and employed in ordinary company), after checking the assumptions of normality and homoscedasticity. In the ANOVA analyses we obtained the effect size via ETA partial square.

We performed univariate logistic regressions for unadjusted effects of each variable for being employed (social company or ordinary employment). In the same way, we obtained unadjusted odds ratio for exclusively being employed in an ordinary company.

Finally, introducing socio-demographic, cognitive and social variables we conducted two logistic regressions in order to obtain fully adjusted effect for both criterion variables: being o not employed and being or not employed in an ordinary company.

\section{Results}

\section{RBANS outcomes}

Raw scores and converted adjusted scores are presented according to the normative population (Randolph, 1998). Index scores have a mean of 100 and a standard deviation of 15. High scores in RBANS mean better cognitive functioning.Participants obtained the following scores on the RBANS:

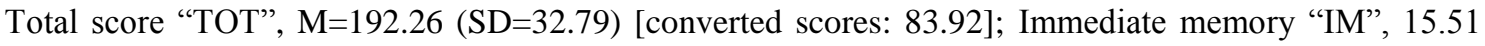
(3.28) [65.43]; Visuospatial "VS", 17.26 (2.27) [97]; Language "LA", 12.97 (2.41) [82.54]; Attention “AT", 20.40 (5.52) [72.67] and Delayed memory "DM", 10.82 (1.89) [81.35]. RBANS scores showed deficient cognitive functioning, particularlyin the "immediate memory" and "attention" scales. There werefewer differences in the "language" and "visuospatial" scales and it is worth highlighting that $13 \%$ of the sample scores were within the mean of the normal population (Randolph, 1998). Specifically, the number of standard deviations of difference from the normal population in $\mathrm{z}$ scores was respectively:"TOT"-1.072; "IM"-2.3; "VS"-0.2; "LA"-0.17; “AT"-1.82; "DM"-1.24. These deviations wereslightly lower than those obtained by Wilk et al. (2004) with a sample of patients with schizophrenia. We can also see, in relation to the instrument, that while the internal validity of the total score is acceptable (Cronbach's alpha of 0.7), there are factors with questionable validity. Thus, "attention", "language" and "visuospatial", werebelow 0.4. However, specific damage patterns of people with SMI may explain these low alphas. RBANS correlated significantly in all its scales with the score of the Mini Mental (although the intensity of the correlation wassmall or medium, between 0.367 with the "overall score" and 0.203 with the "immediate memory" scale). Furthermore, both the Mini Mental and the overall RBANS score correlated negatively with age (-.22 and -.26 respectively).

Association between cognitive and social function, sex and educational level 
Participants with a higher educational level showed higher RBANS' scores. For the variance analysis we checked the suppositions of normality and homoscedasticity (Smirnov-Kolgomorov and Levene tests). In terms of educational level, the omnibus significance by $F$ test was significant with a small effect size for all factors except for language factor. "TOT", $\mathrm{F}_{(2,212)}=10,171, p<.001, \eta^{2}=0.089$; “IM", $\mathrm{F}_{(2,212)}=8.417, p<.001, \eta^{2}=0.075 ;$ "VS", $\mathrm{F}_{(2,212)}=4.883, p=.009, \eta^{2}=0.075 ;$ “AT", $\mathrm{F}_{(2,212)}=6.335$, $p=.002, \eta^{2}=0.058 ;$ "DM", $\mathrm{F}_{(2,212)}=6.066, p=.003, \eta^{2}=0.055$. Performing an adjustment to alpha level (Bonferroni method), only subjects with Baccalaureate-university studies presented a significantly higher score in the RBANS than those with incomplete compulsory studies. The educational level does not seem to be associated with the social functioning measured with the SFS. Significantly, women scored higher than men in "language" and men higher than women in the "visuospatial" index score. In relation to the SFS, women scored higher in "independence-performance".

\section{Association between occupational situation and cognitive and social function}

Regarding differences between the three groups defined by their occupational situation, women and those with a higher educational level wereover-represented among employed people, particularly in ordinary companies. While $17.9 \%(\mathrm{~N}=12)$ of women were employed in ordinary companies "OC"; only $5.5 \%$ (8) of men were employed in this kind of company: $\chi^{2}(2, \mathrm{~N}=213)=10.41, p=.05$. While $26.3 \%(10)$ of people with higher education status (Baccalaureate-University) were employed in "OC", only 4.4\% (6) of people with incomplete primary education were in this situation: $\chi^{2}(2, \mathrm{~N}=213)=35.33, p<.001$.

Those who worked in ordinary companies obtained significantly higher scores and a larger size effect in the total scale score $\left(\mathrm{F}_{(2,212)}=12.512, p<.001, \eta^{2}=0.106\right)$ and in the "attention" $\left(\mathrm{F}_{(2,212)}=12.37\right.$, $\left.p<.001, \eta^{2}=0.105\right)$ factor of the RBANS. This also occurred in "delayed memory" $\left(\mathrm{F}_{(2,212)}=5.984, p=.003\right.$, $\left.\eta^{2}=0.054\right)$ and "immediate memory" $\left(\mathrm{F}_{(2,212)}=6.058, p=.003, \eta^{2}=0.055\right)$ but with a mean effect size. The "language" factor was significant with a small effect size $\left(\mathrm{F}_{(2,212)}=2.927, p=.05, \eta^{2}=0.027\right)$ and without significant post-hoc differences between groups.

The "independence-competence" factor of the SFS was also significant, with a higher score and mean effect size for employees in ordinary companies $\left(F_{(2,212)}=6.189, p=.002, \eta^{2}=0.056\right)$. Using an adjustment to alpha level (Bonferroni method), we observed that the differences in the RBANS factors only affected employees in ordinary companies, with a significance below .01 .

\section{Logistic regression analysis for the criterion variable (being employed or not)}

As for the demographic variables, unadjusted odds ratio for being employed, including social enterprise and ordinary employment, were (only significant effects presented): Sex (women), $\mathrm{p}=.019$, OR 2.03, IC $(95 \%)=1.121-3.682$; Educational level (compulsory education), $\mathrm{p}=<.001$, OR 3.369, $\mathrm{IC}=1.560-7.74$; Educational level (Baccalaureate-university), $\mathrm{p}=<.001$, OR=5.874, IC=2,692-12.815. Significant odds ratios of RBANS' factors were: Language, $\mathrm{p}=.023$, OR 1.156, IC: 1.020-1.307 and Attention, $\mathrm{p}=.000, \mathrm{OR}=1.106, \mathrm{IC}=1.047-1.169$. Significant SFS factors were Independence-Execution, $\mathrm{p}=.046, \mathrm{IC}=1.148, \mathrm{IC}=1.003-1.316$ and Independence-Competence, $\mathrm{p}=.002, \mathrm{OR}=1.264, \mathrm{IC}=1.087-1.469$.

When we introduced all the variables to obtain adjusted effects only three significant OR remained: Educational level (compulsory education), $\mathrm{p}=.008$, adjusted $\mathrm{OR}=3.075, \mathrm{IC}=1,339-7.061$; 
Educational level (Baccalaureate-university), $\mathrm{p}=<.001$, adjusted $\mathrm{OR}=5.419, \mathrm{IC}=2.215-13.262$; Attention, $\mathrm{p}=.018$, adjusted $\mathrm{OR}=1.093, \mathrm{IC}=1.1015-1.177$.

The Hosmer \& Lemeshowda goodness-of-fit test gave a figure of 0.937 and the R-square of Nagelkerke explained $27 \%$ of the variance. The model correctly predicted $73 \%$ of our results.

Logistic regression analysis for the criterion variable (being employed or not in O.C.)

In relation to demographic variables, the unadjusted odds ratio for being employed in ordinary employment were: Sex (women), $\mathrm{p}=.006, \mathrm{OR}=3.736$, IC $(95 \%)=1.448-9.639$; Educational level (Baccalaureate-university), $\mathrm{p}=<.000, \mathrm{OR}=8.148, \mathrm{IC}=2.730-24.320$. Significant odds ratios of RBANS' factors were: Immediate memory, $\mathrm{p}=.002, \mathrm{OR}=1.361$, IC: $1.122-1.652$; Attention, $\mathrm{p}=<.001$, $\mathrm{OR}=1.195$, $\mathrm{IC}=1.093-1.306$, and Differed Memory, $\mathrm{p}=.002, \mathrm{OR}=1.301, \mathrm{IC}=1.103-1.534$. The only significant SFS factor was Independence-Competence, $\mathrm{p}=.036, \mathrm{OR}=1,326, \mathrm{IC}=1.019-1.725$.

When we introduced all the variables we obtained five significant odds ratios. Sex (women), $\mathrm{p}=.005$, adjusted $\mathrm{OR}=6.027, \mathrm{IC}=1.715-21.180$, Educational level (Baccalaureate-university), $\mathrm{p}=.007$, adjusted $\mathrm{OR}=8.106, \mathrm{IC}=1.773-37.068$; Attention, $\mathrm{p}=.018$, adjusted $\mathrm{OR}=1.160, \mathrm{IC}=1.023-1.317$; Communication, $\mathrm{p}=.018$, adjusted $\mathrm{OR}=1.331$, IC=1.049-1.687; Independence-Competence, $\mathrm{p}=.037$; adjusted $\mathrm{OR}=1.539, \mathrm{IC}=1.026-2.308$.

In this second analysis, the variance explained was fairly large, 45.6\% (Nagelkerke's R-square). The Hosmer \& Lemeshowda goodness-of-fit test of the model gave a figure of 0.802 . The model correctly predicted $91.4 \%$ of our results.

\section{Discussion}

The cognitive functioning measured by the RBANS showed important deficits, especially in factors such as memory and attention. Compared with other studies with the RBANS, our scores were higher than those of the normative sample of people with schizophrenia (Wilk et al., 2004) and more in line with those found in other studies (Becker, Bond, Mueser\& Torrey, 2007; Gogos, Joshua \&Rossell, 2010; Han et al., 2012; Loughland et al., 2007), but the differences were probably to do with the composition of the samples studied (outpatient or inpatient care, employment programs, etc.). Our results also showed a strong association of the RBANS score with educational level, which is usual but not always found in other studies (Loughland et al., 2007) and particularly between paid work and good cognitive functioning (Bell \& Bryson, 2001; Giugiario et al., 2012; McGurk \& Mueser, 2004).

We also found relations between factors of social functioning which form part of competences and skills necessary for independent life and employment. Thus, the independence-competence factor was significantly higher in participants with jobs compared to those who were unemployed. Our results therefore tie in with those stating that measurements of social functioning are stronger in this respect than those which assess symptomatology exclusively (Giugiario et al., 2012; Kilian et al., 2012; McGurk \& Mueser, 2004; Ramsay, Stewart \& Compton, 2012).

We found some interesting results concerning the differences between employment in ordinary companies and social enterprises. Those working in ordinary companies showed different and more complex cognitive and social capacities. Demonstrating the importance of cognitive and social 
functioning, our variables in the regression analysis were much better at explaining ordinary employment than employment in social enterprises. Those who work in social enterprises seem to do so by compensating for important deficits in social (independence-competence) and cognitive functioning (attention, immediate memory and, to a lesser degree, delayed memory). Given that our study is crosssectional, it is also possible that being employed in ordinary companies has a positive effect on cognitive functioning. However, our first hypothesis is more succinct: jobs that require better cognitive functioning are held by people with high cognitive functioning.

We know that these cognitive deficits give rise to problems of social and thus occupational functioning (McGurk \& Mueser, 2004) but the regression analyses performed showed that the effects of social and cognitive functioning, although they may have had some degree of interaction, were relatively independent (Addington \& Addington, 1999). Both dimensions must therefore be taken into account in support programs.

As for socio-demographic variables, educational level (non-compulsory secondary education or university studies) weighed heavily in the equation which best explained ordinary employment. In fact, the educational level variable was stronger than cognitive functioning in the two regression equations. The educational level helped to explain not just cognitive aspects, but also sociocultural ones such as the family's financial level and social context (Burke-Miller et al., 2006). Hence, the low educational level of our sample compared to other studies (Waghorn, Saha\& McGrath, 2014) accentuated the social disarray and cognitive problems of our participants. This result reminds us of the need to support the education and training of people with SMI. It is essential to design effective educational programs to compensate for their lack of academic experience. In turn, the fact that the variable "sex" (woman) enters the equation which predicts ordinary employment must be related to the lower neuropsychological deficit, better progression and less negative symptomatology which seems to affect women with schizophrenia (Gogos et al., 2010; Ramsay et al., 2012), it may also be related to the specific employment opportunities found in Andalusia. Similar correlates between sex (being women), high educational level and competitive employment have been found in previous studies (Waghorn, Saha \& McGrath, 2014). In addition, one study found that partnered men were more likely to achieve competitive employment than partnered women (Waghorn, Saha \& McGrath, 2014). Therefore, all these variables should be analyzed via their interaction with cognitive functioning.

The interesting differences found in the cognitive functioning between those who work in social and ordinary companies is to do with the character of both types of employment, but also with the specific characteristics of Andalusia, apart from the effect of social stigma. With a high level of unemployment (over $25 \%$ of the population) ordinary companies give priority to people with good social and cognitive functioning. Social enterprises attempt to make room for people with greater difficulties, compensating their deficits with a more protective and tolerant atmosphere, besides receiving some financial compensation for the lower productivity of some employees (Grove, Freudenberg \& Harding, 1997). The FAISEM model, combining both employment strategies and diversifying supports depending on their respective characteristics seems to be of use, at least in the context of Andalusia.

Our study stems from the consideration of cognitive and social functioning as independent variables which would explain the different employment situations (stronger in the case of ordinary 
employment). However the transversal design does not allow us to consider the complementary hypothesis that employment could function as a factor of functional and cognitive rehabilitation, a reasonable hypothesis to which some recent publications have pointed and which should be substantiated in future studies.

Finally, this study does have certain limitations. The design does not allow a longitudinal analysis or an assessment of the possible causal relations between variables. All participants were diagnosed by the mental health services and complied with severity criteria, and the percentage of different diagnoseswas similar across the three groups. However, we were not able to assess illness severity variables in situ. Even though participants were judged by the mental health services' criteria to have roughly the same levels of illness severity, it is clear that these variables could have a significant effect on results.

\section{Conclusions}

Despite its limitations, the results of the study show the association between the cognitive functioning measured by the RBANS (particularly attention), social functioning measured by the SFS (especially independence-competence) and the proportion of employed people with SMI. The direction of the association is always positive (the better the functioning, the greater the proportion of people employed), with differences in the strength of the association between the two employment situations (social and ordinary companies) within a specific program developed in southern Spain.

Our results emphasize the need to work with the aspects of cognitive and social functioning, to increase the permeability of ordinary companies and to improve the support capacity of social enterprises for people with greater levels of disability.

Competitive employment programs (for instance IPS) have demonstrated efficacy and good outcomes in different studies (Burns, T., Catty, J., Becker, T., Drake, R.R., Fioritti, A., Knapp, M., et al. 2007; Waghorn, Saha \& McGrath, 2014). We argue that the first step should be to try to find jobs in ordinary companies (which could be called 'competitive work'). However, and despite our efforts, the particular characteristics of labor markets coupled with cognitive and social functioning deficits may make its implementation very difficult for some patients. Even in parts of Europe where IPS programs have run intensely, $50 \%$ or $60 \%$ of users fail to get a job. For that reason, some authors have suggested the implementation of "a composite system juggling with various options" (Fioritti, D'Alema, Barone\& Bruschetta, 2014). High quality jobs in social firms as we described in our introduction may represent a solution in these cases. More empirical evidence about the efficacy of this kind of employment needs to be gathered in future research. 


\section{References}

Addington, J., \&Addington, D. (1999).Neurocognitive and Social Functioning in Schizophrenia.SchizophreniaBulletin 25(1): 173-182.

Alonso, J., Olivares, J.M., Ciudad, A., Manresa, J.M., Casado, A., \&Gilaberte, I. (2008). Desarrollo y validación de la versión corta de la Escala de Funcionamiento Social en esquizofrenia para su uso en la práctica clínica. Actas Españolas de Psiquiatría 36:102-110.

August, S.M., Kiwanuka, J.N., McMahon, R.P., \& Gold, J.M. (2012).The MATRICS ConsensusCognitiveBattery (MCCB): clinical and cognitivecorrelates. Schizophrenia Research $134: 76-82$

Becker, D., Bond, G., Mueser, K., \& Torrey, W. (eds.) (2007).SupportedEmploymentWorkbook.SAMHSA, 2003.Versiónespañolaen FAISEM.Guía para el desarrollo de programas de empleo con apoyo para personas con trastorno mental grave. FAISEM, Sevilla.

Bell, M.D., \&Bryson, Q. (2001).Work rehabilitation in schizophrenia: Does cognitive impairment limit improvement? Schizophrenia Bulletin 27:269-279.

Birchwood, M., Smith, J., Cochrane, R., Wetton, S., \&Copestake, S. (1990).The Social Functioning Scale.The development and validation of a new scale of social adjustment for use in family intervention programmes with schizophrenic patients.The British Journal of Psychiatry 157:853-859.

Boardman, J., Grove, B., Perkins, R., \& Shepherd, G. (2003).Work and employment for people with psychiatric disabilities.The British Journal of Psychiatry 182:467-468.

Bond, G.R., Drake, R.E., \& Becker, D.R. (2008). An update on randomized controlled trials of evidencebased supported employment. Psychiatric Rehabilitation Journal 31:280-290.

Burns, T., Catty, J., Becker, T., Drake, R.R., Fioritti, A., Knapp, M., et al. (2007). The effectiveness of supported employment for people with severe mental illness: a randomized controlled trial. The Lancet, 370: 1146-1152.

Burke-Miller, J. K ., Cook, J. A., Grey, D. D., Razzano, L. A., Blyler C.R., Leff, H.S. et al. (2006) Demographic Characteristics and Employment Among People with Severe Mental Illness in a Multisite Study. Community Mental Health Journal 42, 2: 143-159. 
Burns, T., Catty, J., White, S., Becker, T., Koletsi, M., Fioritti, A., Rössler, W., Tomov, T., van Busschbach, J., Wiersma, D., \&Lauber C. (2009). The impact of supported employment working on clinical and social functioning: results of an international study of individual placement and support. Schizophrenia Bulletin 35:949-959.

Butler, G., Howard, L., Choi, S., \&Thornicroft, G. (2010).Characteristics of people with severe mental illness who obtain employment.The Psychiatrist 34:47-50.

Fioritti, A., D’Alema, M., Barone, R., Bruschetta, S. (2014). Social Enterprises, vocational rehabilitation, supported employment. The Journal of Nervous and mental Disease, 202: 498-500.

Folstein, M.F., Folstein, S.E., \& McHugh, P.R. (1975)."Mini-mental state".A practical method for grading the cognitive state of patients for the clinician. Journal of Psychiatric Research, 12(3):189-198.

Gilbert, E., Marwaha, S., Milton, A., Johnson, S., Morant, N., Parsons, N., et al. (2007). Social firms as a means of vocational recovery for people with mental illness: a UK survey. BMC health Services research, 13: $270-279$.

Giugiario, M., Crivelli, B., Mingrone, C., Montemagni, C., Scalese, M., Sigaudo, M., Rocca, G., \& Rocca, P. (2012). Cognitive function and competitive employment in schizophrenia: relative contribution of insight and psychopathology. Social Psychiatry and Psychiatric Epidemiology 47:553-561.

Gogos, A., Joshua, N., \&Rossell, S. (2010). Use of the Repeatable Battery for the Assessment of Neuropsychological Status (RBANS) to investigate group and gender differences in schizophrenia and bipolar disorder. Australian and New Zealand Journal of Psychiatry 44:220229.

Gold, J.M., Queern, C., Iannone, V.N., \& Buchanan, R.W. (1999). Repeatable Battery for the Assessment of Neuropsychological Status as screening test in Schizophrenia, I: sensitivity, reliability and validity. American Journal of Psychiatry 156:1944-1950.

Green, M.F. (2006). Cognitive impairment and functional outcome in schizophrenia and bipolar disorder.Journal of Clinical Psychiatry 67(suppl.):3-8.

Green, M.F., Kern, R.S., Braff, D.L., \&Mintz, J. (2000).Neurocognitive deficits and functional outcome in schizophrenia: are we measuring the "right stuff"? Schizophrenia Bulletin 26:119-136.

Grove, B., Freudenberg, M., \& Harding, A., (1997).The social firm handbook.Pavilion, Brighton. 
Han, M., Huang, X.F., Chen, D.C., Xiu, M.H., Hui, L., Liu, H., Kosten, T.R., \& Zhang, X.Y. (2012).Gender differences in cognitive function of patients with chronic schizophrenia. Progress in Neuro-Psychopharmacology and Biological Psychiatry, 39:358-363.

Hobart, M.P., Goldberg, R., Bartko, J.J., \& Gold, J.M. (1999).Repeatable Battery for the Assessment of Neuropsychological Status as screening test in Schizophrenia, II: convergent/discriminant validity and diagnostic group comparisons. American Journal of Psychiatry 156:1951-1957.

Kaneda, Y., Jayathilak, K., \& Meltzer, H.Y. (2009). Determinants of work outcome in schizophrenia and schizoaffective disorder: role of cognitive function. Psychiatric Research 169:178-179.

Kilian, R., Lauber, C., Kalkan, R., Dorn, W., Rössler, W., Wiersma, D., van Buschbach, J.T., Fioritti, A., Tomov, T., Catty, J., Burns, T., \& Becker, T. (2012). The relationships between employment, clinical status, and psychiatric hospitalization in patients with schizophrenia receiving either IPS or a conventional vocational rehabilitation program.Social Psychiatry and PsychiatricEpidemiology 47:1381-1389.

Lobo, A., Saz, P., Marcos, G., Día, J.L., de la Cámara C., Ventura, T., Morales, F., Pascual, L.F., Montañés, J.A., \& Aznar, S. (1999). Revalidación y normalización del Mini-Examen cognoscitivo (primera versión en castellano del Mini-Mental Status Examination) en la población general geriátrica. Revista de Medicina Clínica de la Universidad de Barcelona 112:767-774.

López, M. (2010). El empleo y la recuperación de personas con trastornos mentales graves. La experiencia de Andalucía. Revista Norte de Salud Mental 36:11-23.

Loughland, C.M., Lewin, T.J., Carr, J., Sheedy, J., \& Harris, A.W. (2007). RBANS neuropsychological profiles within schizophrenia samples recruited from non-clinical settings. Schizophrenia Research 89:232-242.

Lysaker, P.H., Davis, L.H., Bryson, G.J., \& Bell, M.D. (2009). Effects of cognitive behavioral therapy on work outcomes in vocational rehabilitation for participants with schizophrenia spectrum disorders. Schizophrenia Research 107:186-191.

McGurk, S.R., \&Mueser, K.T. (2003).Cognitive functioning and employment in severe mental illness.The Journal of Nervous and Mental Disease 191:789-798.

McGurk, S.R., \&Mueser, K.T. (2004).Cognitive functioning, symptoms, and work in supported employment: a review and heuristic model. Schizophrenia Research 70:147-173. 
McGurk, S.R., Mueser, K.T., De Rosa, T.J., \& Wolfe, R. (2009).Work, recovery, and comorbidity in schizophrenia: a randomized controlled trial of cognitive remediation. Schizophrenia Bulletin $35: 319-335$.

McGurk, S.R., \&Wykes, T. (2008).Cognitive remediation and vocational rehabilitation. PsychiatricRehabilitation Journal 31:350-359.

Mueser, K.T., Salyers, M.P., \&Mueser, P.R. (2001).A prospective analysis of work in schizophrenia.Schizophrenia Bulletin 27:281-296.

Perkins, D.V., Raines J.A., Tschopp, M.K., \& Warner T.C. (2009). Gainful Employment Reduces Stigma Toward People Recovering from Schizophrenia. Community Mental Health Journal 45:158162

Provencher, H.P., Gegg, R., Mead, S., \&Mueser, K.T. (2002). The role of work in recovery of persons with psychiatric disabilities.Psychiatric Rehabilitation Journal 26:132-144.

Ramsay, C.E., Stewart, T., \& Compton, M.T. (2012).Unemployment among patients with newly diagnosed first-episode psychosis: prevalence and clinical correlates in a US sample. Social Psychiatry and Psychiatric Epidemiology 47:797-803.

Randolph, C. (1998). Repeatable Battery for the Assessment of Neuropsychological Status (RBANS): Test Manual. San Antonio, Harcourt Brace and Company.

Ruggieri, M., Leese, M., Thornicroft, G., Bisoffi, G., \&Tansella, M. (2000).Definition and prevalence of severe and persistent mental illness.The British Journal of Psychiatry 177:149-155.

Waghorn, G., Saha, S., \& McGrath, J.J. (2014).Correlates of competitive versus nomcompetitive employment among adults with psychotic disorders.Psychiatric Services 65: 476-482.

Warner, R., \&Mandiberg, J. (2006).An update on affirmative businesses or social firms for people with mental illness.Psychiatric Services 57:1488-1492.

WHO (2013) Comprehensive mental health action plan 2013-2020. Resolution WHA 66/8. Available at:http://apps.who.int/gb/ebwha/pdf_files/WHA66/A66_R8-en.pdf. Accessed 27/12/13.

Wilk, C.M., Gold, J.M., Humber, K., Dickerson, F., Fenton, W.S., \& Buchanan, R.W. (2004). Brief cognitive assessment in schizophrenia: normative data for the Repeatable Battery for the Assessment of Neuropsychological Status. Schizophrenia Research 70:175-186. 